\title{
The Role of Immediate Fine Needle Aspiration Cytology by Specialist Head and Neck Surgeons in a "One-Stop" Clinic: A Single-Centre Retrospective Analysis.
}

\section{Ahanger $S^{1}$, Ankrah $L R^{1}$, Darr $A^{1}$, Jolly $K^{1}$, Ahsan SF 1 Shrewsbury and Telford NHS Trust}

\section{Introduction}

Fine needle aspiration (FNA) is a quick and cost effective tool with the ability to provide a minimally invasive preliminary diagnosis. FNA allows differentiation between inflammatory, cystic and neoplastic lesions.

\section{Objective}

To assess the use of a dedicated "one-stop" neck lump clinic, by specialist head and neck surgeons, in improving the adequacy of fine-needle aspiration cytology (FNAC) samples.

\section{Method}

-38 month retrospective period selected at a single centre

- Patients who had attended a neck lump clinic with a neck lump, excluding thyroids, in this time were identified

- Retrospective analysis of FNAC and subsequent interventions conducted

\section{Results}

-129 patients identified in accordance with inclusion criteria, as stated in the method.

Graph to show the number of days from initial appointment to return of cytology results and the number of cases attributable to that time frame.

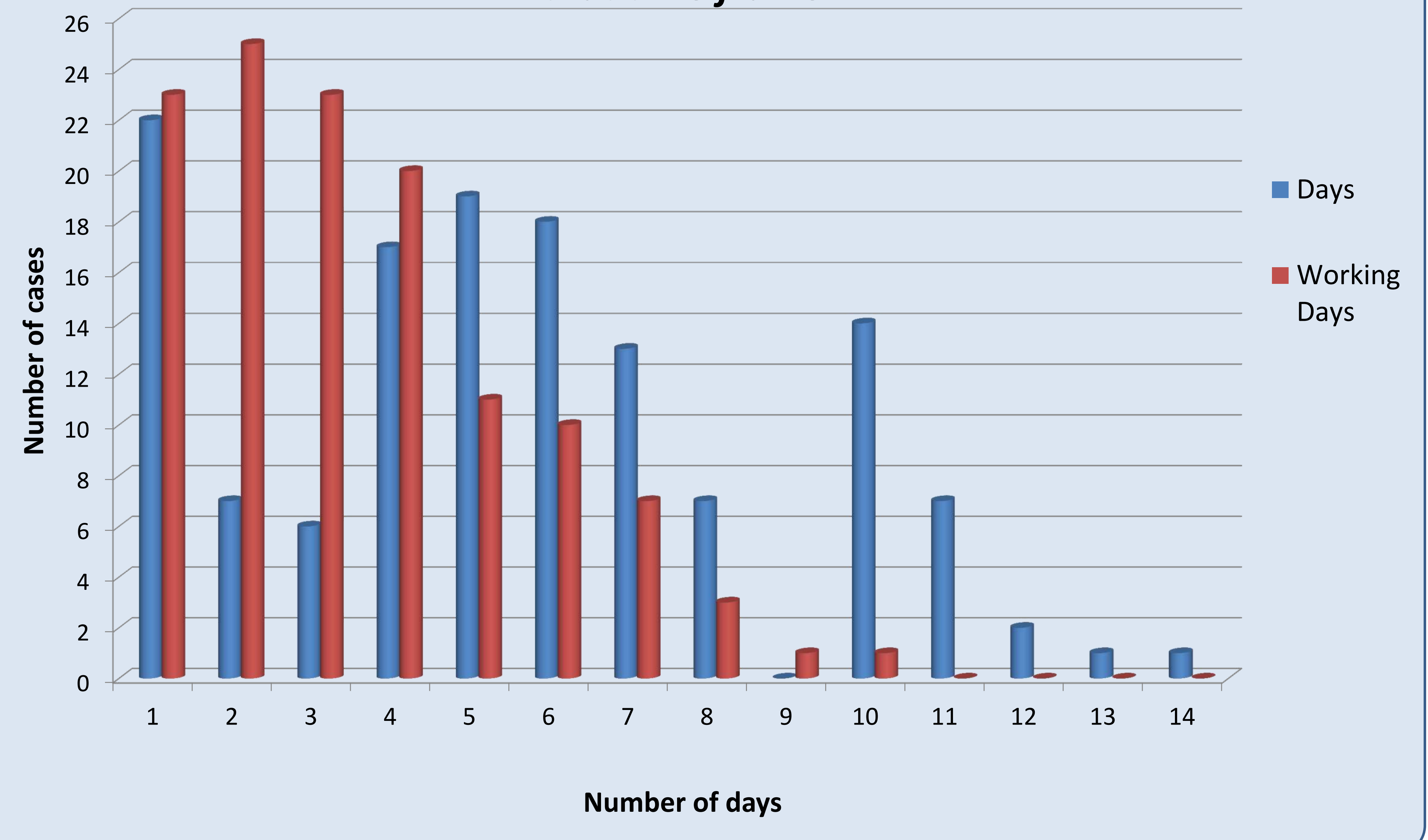

- The mean number of full days from appointment to cytology result - 5 days (range $1-14$ )

- The mean number of working days from appointment to cytology result - 3 days (range 1-10)

\section{FNAC Sample Outcomes}

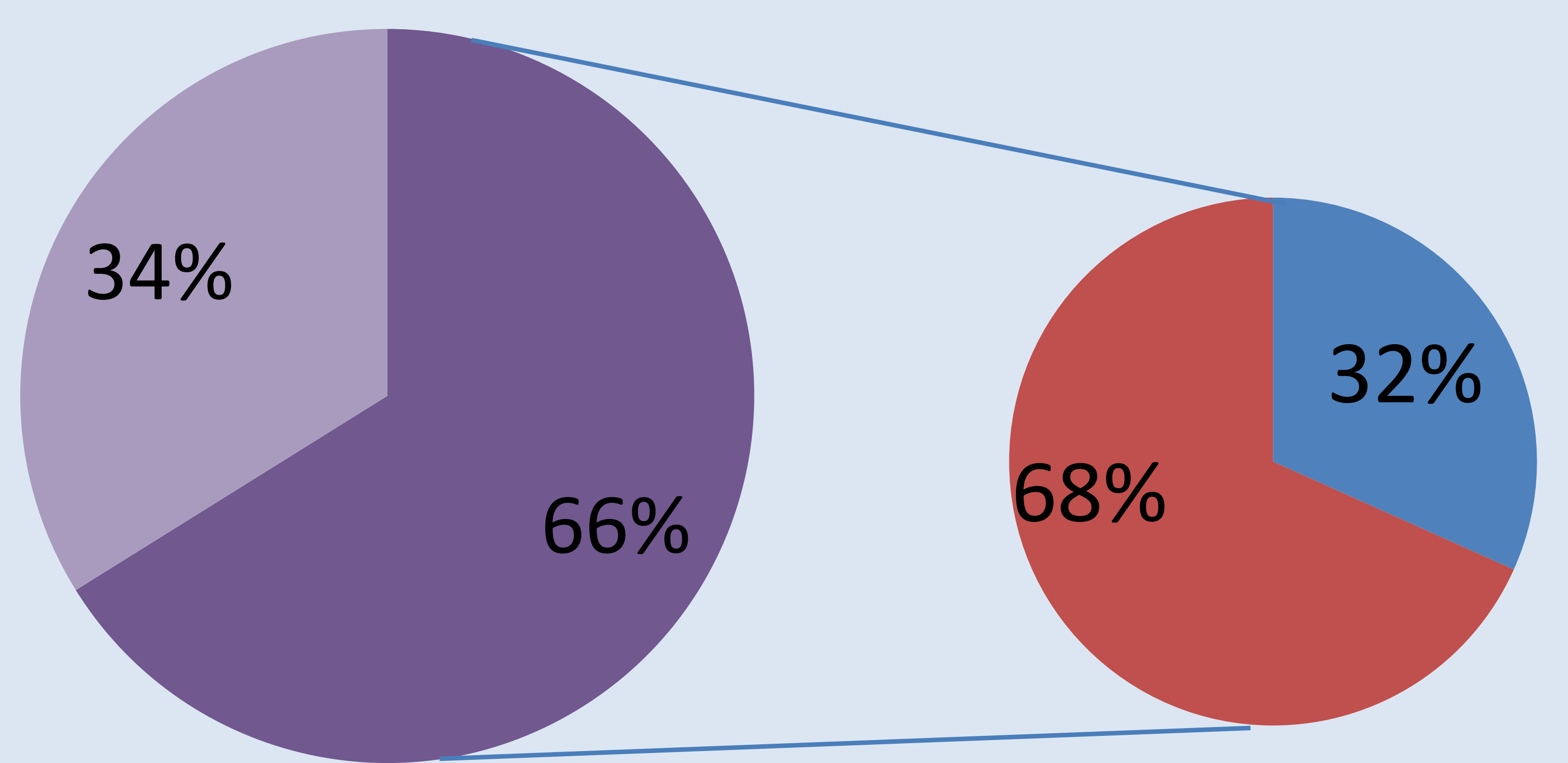

Sample sufficient

Sample Insufficient for analysis

Not Diagnostic Diagnostic

- $89 \%$ of patients had formal imaging following FNA $(n=116)$

- No available literature on the efficacy of fine needle aspiration, on lumps other than thyroids, performed solely by Head and Neck surgeons in the UK

\section{Conclusion}

Our study demonstrates:

- Resource permitting, immediate FNAC within experienced hands provides sufficient diagnostic adequacy, in accordance to published standards.

- That a subsequent reduction in diagnostic delay permits prompt intervention in patients with confirmed malignancy, with the need for minimal additional resources. 